\title{
THE EFFECT OF $\omega$-FATTY ACIDS ON mRNA EXPRESSION LEVEL OF PPARY IN PATIENTS WITH GASTRIC ADENOCARCINOMA
}

\author{
A. Hosseinzadeh', M.-H. Somi', H. Dolatkhah ${ }^{3}$, A. Esfahani, H.S. Kafil', S.M.M. Ardebili, ${ }^{6}{ }^{4}$ \\ ${ }^{1}$ Department of Biology, East Azarbaijan Science and Research Branch, Islamic Azad University, Tabriz 51388, Iran \\ ${ }^{1}$ Department of Biology, Tabriz Branch, Islamic Azad University, Tabriz 51388, Iran \\ ${ }^{2}$ Liver and Gastrointestinal Disease Research Center, Tabriz University of Medical Sciences, Tabriz 51368, Iran \\ ${ }^{3}$ Department of Clinical Biochemistry, Faculty of Medicine, Tabriz University of Medical Sciences, Tabriz 51368, Iran \\ ${ }^{4}$ Department of Internal Medicine, Faculty of Medicine, Tabriz University of Medical Sciences, Tabriz 51368, Iran \\ ${ }^{5}$ Department of Medical Microbiology, Faculty of Medicine, Tabriz University of Medical Sciences, Tabriz, 51368, Iran \\ ${ }^{6}$ Department of Medical Genetics, Faculty of Medicine, Tabriz University of Medical Sciences, Tabriz 51368, Iran
}

Background: The antineoplastic role of peroxisome proliferator-activated receptor gamma (PPAR $\gamma$ ) ligandshas previously been demonstrated in several gastric cancer cell lines. Activation of PPAR $\gamma$ by polyunsaturated fatty acids (PUFAs) inhibits growth and proliferationof tumor cells. In this double-blind clinical study, we evaluate the effect of PUFAs on PPAR $\gamma$ mRNA expression in patients with gastric adenocarcinoma. Materials and Methods: A total of 34 chemotherapy-naive patients diagnosed with gastric adenocarcinoma were enrolled in the present study. According to treatment strategies, all subjects were divided into two groups, the first group (17 individuals) received cisplatin without supplements and the second group (17 individuals) received cisplatin plus orally administered PUFAs supplements for 3 weeks. The gastric biopsy samples were obtained from all participants before and after treatment, and PPAR $\gamma$ mRNA expression levels were evaluated by quantitative real-time polymerase chain reaction using validated reference genes. Results: Our findings revealed that PPAR $\gamma$ mRNA expression is significantly upregulated in group II afterreceiving cisplatin plus orally administered PUFAs supplements for three weeks $(p<0.0001)$, whereas PPAR $\gamma$ mRNA expression did not show significant alteration in group I after receiving cisplatin alone. Conclusion: The results of the study evidence that PPAR $\gamma$ may act as a potential target for the therapy of human gastric adenocarcinoma.

Key Words: peroxisome proliferator-activated receptor gamma, PPAR $\gamma$, PUFAs, gastric cancer.

Gastric cancer is the fourth most common cancer among both men and women in the world [1, 2]. According to Cancer Facts and Figures, by the American Cancer Society, in 2015, 24,590 estimated new cases of gastric cancer will be diagnosed, and 10,720 deaths will occur in the United State [3]. Although, the incidence and mortality rate of gastric cancer have decreased dramatically in many nations, it still ranks $2^{\text {nd }}$ as the leading cause of cancer related deaths globally [4]. In Iran with about 8000 deaths annually, gastric cancer remains the first cause of cancer related death in both sexes [5]. It is evidenced that gastric cancer is a complicated and multifactorial disease, which is caused by inherited and acquired risk factors $[2,6]$. The best known risk factors for gastric cancer include Helicobacter pylori infection, chronic atrophic gastritis, hypertrophic gastropathy, gastric polyps, obesity, endogenous formation of $\mathrm{N}$-nitroso compounds, high salt intake, and malnutrition of antioxidants [2, 7]. In the last decades, widespread molecular studies have been performed to discover the detailed molecular mechanisms which involved in development and progression of gastric cancer [8-12]. Although, these investigations have been unearthed more clues of the gastric cancer nature which may be lead us towards treatment of can-

Submitted: August 17, 2016.

${ }^{\star}$ Correspondence: E-mail: Aliasgharh68@gmail.com

Abbreviation used: PPARs - peroxisome proliferator-activated receptors; PPRE - peroxisome proliferator response element; PUFAs - polyunsaturated fatty acids; RXR - retinoid X receptor. cer and introduce anticancer drugs, the most puzzling facets of gastric cancer is still remained enigmatic.

Peroxisome proliferator-activated receptors (PPARs) belong to a subfamily of the steroid nuclear hormone receptor superfamily of ligand-activated intracellular transcription factors [13]. To date, three different isoforms of PPARs (PPARa, PPAR $\beta / 6$ and PPAR $\gamma$ ) have been identified, each with tissue specific distribution and ability to interact with diverse classes of compounds [14]. PPARy regulates the expression of myriad genes that modulate energy metabolism, inflammatory response, cell differentiation, and apoptosis [15]. When activated by specific ligands, PPARY heterodimerizes with the retinoid $X$ receptor ( $R X R$ ) to form a complex (PPAR/RXR) and regulates expression of target genes by binding to the peroxisome proliferator response element (PPRE) [16]. The target genes that are transcriptionally activated by PPARY regulate multiple signaling pathways, including those related to p21, p53, nuclear factor $\mathrm{KB}, \mathrm{BCL} 2, \mathrm{STAT}$, and cyclin D1 [17]. The ability of PPARy to regulate the expression of genes involved in cell differentiation, cell cycle control and apoptosis allows to propose that altered expression of PPARy may be associated with tumorigenesis [18]. Compounds that activate PPARy comprise the heterogeneous group that includes polyunsaturated fatty acids (PUFAs) and eicosanoids, as well as synthetic activators [19]. Anticancer effects of PPARy ligands have been reported in several gastric cancer cell lines, an effect attributed to induction of apoptosis, cell cycle arrest and inhibition of growth and proliferation [20]. However, the role 
of orally administered PUFAs supplements on PPARy mRNA expression in gastric cancer has not been investigated in depth. Therefore, we designed a double-blind clinical study in patients with gastric adenocarcinoma to investigate the effect of PUFAs on PPARy mRNA expression.

\section{MATERIALS AND METHODS}

Subjects. A total of 34 chemotherapy-naive patients with histologically and/or cytologically confirmed gastric adenocarcinoma were recruited from Liver and Gastrointestinal Diseases Research Center and Hematology-Oncology Research Center, Tabriz, Iran, during 2013-2015. The patients with diabetes, pyloric obstruction, cardiac obstruction, renal dysfunction and inflammatory diseases were excluded from the study. Eligible subjects were assigned to one of two groups in a double-blind manner. Group I (17 individuals; mean age, $67.5 \pm 11.2$ years) received cisplatin without supplements $\left(50 \mathrm{mg} / \mathrm{m}^{2}\right.$ intravenous per 4 weeks for 3 months), while Group II (intervention group) (17 individuals; mean age, $71.3 \pm 9.8$ years) received cisplatin plus orally administered PUFAs supplements (Natural Factors Omega Factors Ultimate 1200 mg capsules, supplements of $\omega-3, \omega-6$, and $\omega-9$ fatty acids with the formula of fish oil blend $400 \mathrm{mg}$, flax seed oil $400 \mathrm{mg}$, borage oil $400 \mathrm{mg}$ ) in the scale of $3600 \mathrm{mg}$ per day for 3 weeks. Demographic and clinical properties of two groups are shown in Table 1. The present study was approved by the Ethics and Human Rights Committee of Tabriz University of Medical Sciences, Tabriz, Iran, and the informed consents were filled out by all participants.

RNA extraction and cDNA synthesis. All gastric biopsy samples were stored in RNAlater solution (Qiagen, Germany) at $-80{ }^{\circ} \mathrm{C}$ until RNA extraction. Total RNA was isolated from tissue samples using RNeasy kit (Qiagen, Valencia, CA) and RNA yield was treated with RNase-free DNase (MBI Fermentas, Canada), according to the manufacturer's instructions. The quality and quantity of extracted RNA were confirmed by agarose gel electrophoresis and NanoDrop ${ }^{\circledR}$ ND1000 Spectrophotometer (Thermo Scientific, USA), respectively. Subsequently, total RNA $(1 \mu \mathrm{g})$ was reversely transcribed to cDNA using RevertAid ${ }^{\mathrm{TM}}$ First Strand cDNA Synthesis Kit (Fermentas, Canada) with random hexamer primer, following the manufacturer's protocol.

Quantitative real-time polymerase chain reaction (PCR). Real-time PCR was conducted in triplicate using gene-specific primers as shown in Table 2 and SYBR Green (SYBR Premix Ex Taq RT-PCR kit, Takara) by the Rotor-Gene ${ }^{\mathrm{TM}} 6000$ system (Corbett Research, Australia) according to the manufacturer's instructions. Each reaction mixture contained 100 ng cDNA, master mix 2X, ROX dye 50X, and 10 pmol of each primer pairs for PPARy and GAPDH in a final volume of $25 \mu \mathrm{l}$. Initial denaturation at $94^{\circ} \mathrm{C}$ for 5 min was followed by 50 cycles (for PPARy) and 35 cycles (for GAPDH) of denaturation at $94{ }^{\circ} \mathrm{C}$ for $10 \mathrm{~s}$, annealing at temperatures that are mentioned in Table 2 for each primer pairs for $15 \mathrm{~s}$, extension at $72{ }^{\circ} \mathrm{C}$ for 20 s. Standard curves were plotted using serially diluted cDNA and the expression levels of PPARy in the samples were normalized through the mean expression of the house keeping gene GAPDH. We also used no template negative control.

Table 1. Demographic and clinical properties of the subjects

\begin{tabular}{|c|c|c|c|}
\hline Characteristic & $\begin{array}{r}\text { All subject } \\
\text { Group I }(\mathrm{n}=17)^{\mathrm{a}}\end{array}$ & $\begin{array}{l}\operatorname{ts}(n=34) \\
\text { Group II }(n=17)^{b}\end{array}$ & $p$ value $^{c}$ \\
\hline Age, years & $67.5 \pm 11.21$ & $71.25 \pm 9.81$ & 0.235 \\
\hline Gender & & & 0.695 \\
\hline Male $(n=19)$ & 9 & 10 & \\
\hline Female $(n=15)$ & 8 & 7 & \\
\hline Tumor stage & & & 0.809 \\
\hline$I(n=7)$ & 4 & 3 & \\
\hline$\|(n=11)$ & 6 & 5 & \\
\hline III $(n=9)$ & 4 & 5 & \\
\hline IV $(n=7)$ & 3 & 4 & \\
\hline Tumor primary location & & & 0.714 \\
\hline Upper $(n=11)$ & 5 & 6 & \\
\hline Median $(n=13)$ & 6 & 7 & \\
\hline Lower $(n=10)$ & 6 & 4 & \\
\hline Tumor size & & & 0.759 \\
\hline$\leqslant 4 \mathrm{~cm}(\mathrm{n}=16)$ & 7 & 9 & \\
\hline$>4 \mathrm{~cm}(\mathrm{n}=18)$ & 10 & 8 & \\
\hline Familial history of gastric cancer & & & 0.730 \\
\hline Yes $(n=19)$ & 9 & 10 & \\
\hline No $(n=15)$ & 8 & 7 & \\
\hline Smoking status & & & 0.714 \\
\hline Current smoker $(\mathrm{n}=12)$ & 6 & 6 & \\
\hline Second smoker $(n=11)$ & 4 & 7 & \\
\hline Never-smoker $(n=11)$ & 7 & 4 & \\
\hline Systolic blood pressure, mmHg & $131.1 \pm 9.20$ & $128.8 \pm 10.20$ & 0.235 \\
\hline Diastolic blood pressure, $\mathrm{mmHg}$ & $85.10 \pm 7.10$ & $79.20 \pm 7.90$ & 0.985 \\
\hline Fasting glucose, $\mathrm{mg} / \mathrm{dl}$ & $98.54 \pm 15.25$ & $102.85 \pm 18.65$ & 0.234 \\
\hline Cholesterol, mg/dl & $148.98 \pm 21.56$ & $151.25 \pm 25.65$ & 0.125 \\
\hline Triglyceride, mg/dl & $87.25 \pm 18.25$ & $78.25 \pm 15.65$ & 0.256 \\
\hline
\end{tabular}

Note: Continuous variables were expressed as mean \pm standard deviation (SD). ${ }^{a}$ Group I; received cisplatin without supplements. ' $G$ roup II; received cisplatin plus orally administered PUFAs supplements (Natural Factors Omega Factors Ultimate $1200 \mathrm{mg}$ capsules, supplements of $\omega-3, \omega-6$, and $\omega-9$ fatty acids with the formula of fish oil blend $400 \mathrm{mg}$, flax seed oil $400 \mathrm{mg}$, borage oil $400 \mathrm{mg}$ ) in the scale of $3600 \mathrm{mg}$ per day for three weeks. 'Evaluated by One way ANOVA and Fisher's $\chi^{2}$ tests.

Table 2. Sequence of primers used in quantitative real-time PCR, the amplicon sizes and the annealing temperature of each reaction

\begin{tabular}{|c|c|c|c|}
\hline Gene & Sequence of primers & $\begin{array}{l}\text { Amplicon } \\
\text { size (bp) }\end{array}$ & $\begin{array}{l}\text { Annealing } \\
\text { temperature } \\
\left({ }^{\circ} \mathrm{C}\right)\end{array}$ \\
\hline PPARY & $\begin{array}{l}\text { F5'-CTTCTCCAGCATTTCTACTCCAC-3' } \\
\text { R5'-GCAGGCTCCACTTTGATTG-3' }\end{array}$ & 126 & 60 \\
\hline GAPDH & $\begin{array}{l}\text { F5'-GAAGGTGAAGGTCGGAGTC-3' } \\
\text { R5'-GAAGATGGTGATGGGATTTC-3' }\end{array}$ & 218 & 60.5 \\
\hline
\end{tabular}

Statistical analysis. Statistical analysis was performed using SPSS software version 16.0 (SPSS Inc., Chicago, IL, USA). Analysis of the distribution of PPARY mRNA expression levels around cutoff points using Kolmogorov - Smirnov test showed that the data were normally distributed and thus, parametric statistical tests were used to compare the data. We used Student's $t$-test to determine the statistically significant difference in the expression of PPARy before and after treatment in both groups. $p$ Values $<0.05$ were considered statistically significant.

\section{RESULTS}

We investigated the mRNA expression level of PPARy in 34 patients diagnosed with gastric adenocarcinoma before and after treatment with cisplatin alone and cisplatin plus orally administered PUFAs supplements using quantitative real-time PCR method, and the ratio of the PPARy expression analyzed 
by the $2^{-\Delta \Delta c t}$ method. Initial analysis of the distribution of PPARy mRNA expression level using Kolmogorov Smirnov test showed that the data were normally distributed $(p<0.001)$. Therefore, the median ratio of PPARy expression level was chosen as the cut-off value in subsequent analysis (Table 3 ).

Table 3. PPARy expression level in two groups

\begin{tabular}{lccccc}
\hline & \multicolumn{4}{c}{ PPARy mRNA expression } & \\
\cline { 2 - 5 } & \multicolumn{3}{c}{ Before treatment } & \multicolumn{2}{c}{ After treatment } \\
\hline Patients & Median & Range & Median & Range & $p$ value $^{\mathrm{a}}$ \\
Group I $^{\mathrm{b}}$ & 0.880 & $0.51-1.20$ & 0.970 & $0.58-1.50$ & 0.331 \\
Group II $^{\mathrm{c}}$ & 0.810 & $0.38-1.26$ & 1.60 & $0.80-2.30$ & 0.0001 \\
\hline
\end{tabular}

Note: ${ }^{a} p$ value calculated by Student's $t$-test. ' $G$ roup I - received cisplatin without supplements. 'Group II - received cisplatin plus orally administered PUFAs supplements (Natural Factors Omega Factors Ultimate 1200 mg capsules, supplements of $\omega-3, \omega-6$, and $\omega-9$ fatty acids with the formula of fish oil blend $400 \mathrm{mg}$, flax seed oil $400 \mathrm{mg}$, borage oil $400 \mathrm{mg}$ ) in the scale of $3600 \mathrm{mg}$ per day for three weeks.

Our results demonstrated that the mRNA expression level of PPARy did not show significant alteration in patients treated with cisplatin alone, before and after treatment $(p=0.331$ ) (Table 3, Figure). The median ratio of PPARy expression in group I patients before and after treatment were 0.88 (range 0.51-1.20) and 0.97 (range $0.58-1.50$ ), respectively (Table 3 ). We found that the mRNA expression level of PPARy was upregulated in patients treated with cisplatin plus orally administered PUFAs supplements (Table 3, Figure). Comparison of the PPARy expression level before and after treatment with cisplatin plus orally administered PUFAs supplements in group II using Student's $t$-test indicated that there is statistical significant difference between them $(p<0.0001)$ (Table 3, Figure). The median ratio of PPARy expression in group II patients before and after treatment were 0.81 (range $0.38-1.26$ ) and 1.60 (range $0.80-2.30$ ), respectively (Table 3 ).

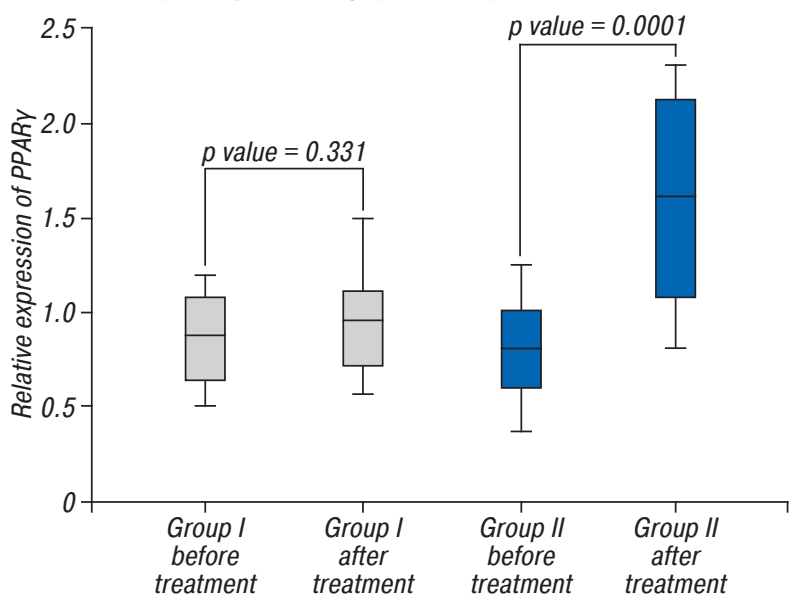

Figure. Box plot graph depicting the mRNA PPARy expression levels in both groups before and after treatment. Group I - received cisplatin without supplements and Group II — received cisplatin plus orally administered PUFAs supplements

\section{DISCUSSION}

Owing to the critical role of PPARy in cell cycle progression, cell differentiation and apoptosis, a large body of researches has been focused on PPARY as a putative target for the prevention and treatment of cancer [21, 22]. However, the precise role of PPARY in carcinogenesis is not very well understood. The antineoplastic activity of PPARY ligands in gastric cancer has been reported by P.C. Konturek et al. [23]. Accordingly, in the present study we investigated the effect of PUFAs on PPARy mRNA expression in patients with gastric adenocarcinoma. Our results revealed that PPARy mRNA expression level is significantly upregulated in patients who were treated with cisplatin plus orally administered PUFAs supplements $(p<0.0001)$. In line with our data, previous studies showed that activation of the PPARy inhibits proliferation, and in some cases induces apoptosis in gastric cell lines [24-27]. Takahashi et al. [24] has reported that troglitazone, as a PPARY ligand, transactivated the transcription of a peroxisome proliferator response element-driven promoter in human gastric cancer cell line, MKN45. The authors concluded that PPARy activation suppresses cell growth and induce apoptosis in gastric cancer cells [24]. The inhibitory effects of PPARY agonists (troglitazone and 15-deoxy-Delta $(12,14)$ prostaglandin $\mathrm{J} 2$ ) on the proliferation of the gastric cancer cells has been suggested by H. Sato et al. [25]. They proposed that induction of apoptosis together with $\mathrm{G} 1$ cell cycle arrest may be one of the mechanisms of the antiproliferative effect of PPARY activation in human gastric cancer cells [25]. Y.X. Chen et al. [26] investigated the effect of PPARy ligand, 15-deoxy-12, 14-prostaglandin $\mathrm{J} 2$ on the proliferation and apoptosis of MCG-803 human gastric cancer cell lines, and reported that this ligand inhibits cell growth and induces apoptosis of MCG-803 cells. In another study, it has been shown that troglitazone inhibits gastric carcinogenesis in mice through PPARy activation [27]. In light of these studies and our data, it seems that PUFAs, as a ligand of PPARY, could inhibit progression and development of gastric cancer through upregulation of PPARy mRNA expression. However, C.W. Cheon et al. [28] proposed that troglitazone and ciglitazone inhibit the proliferation of SNU-216 and SNU-668 gastric cancer cells through a PPARY independent pathway. When they used GW9662, an antagonist of PPARY, in conjunction with ciglitazone and troglitazone, the cell growth suppression effect was unaffected [28]. X.M. Ma et al. [29] also reported that PPARy agonist 15-deoxy-Delta12,14-prostaglandin J(2) suppresses growth of human gastric carcinoma MGC803 cells by inducing apoptosis and G1/G0 cell cycle arrest with the involvement of survivin, Skp2 and p27 and not via PPARY. Therefore, further studies may be required to discover the exact molecular basis of the activities regulated by PUFAs such as PPARY activation on gastric tumor behavior.

In conclusion, our findings showed that treatment based on orally administered PUFAs supplements leads to upregulation of PPARy expression in patients with gastric adenocarcinoma. These data provide additional evidence to support the hypothesis that PPARY may act as a potential target for the therapy of human gastric adenocarcinoma. 


\section{CONFLICT OF INTEREST}

There are no potential conflicts of interest for each author, concerning the submitted manuscript.

\section{ACKNOWLEDGMENTS}

The authors would like to express the sincerest appreciation to all the subjects for participating in this study.

\section{REFERENCES}

1. de Martel C, Forman D, Plummer M. Gastric cancer: epidemiology and risk factors. Gastroenterol Clin North Am 2013; 42: 219-40.

2. Karimi P, Islami F, Anandasabapathy $S$, et al. Gastric cancer: descriptive epidemiology, risk factors, screening, and prevention. Cancer Epidemiol Biomarkers Prev 2014; 23: 700-13.

3. Siegel RL, Miller KD, Jemal A. Cancer statistics, 2015. CA Cancer J Clin 2015; 65: 5-29.

4. Mottaghi-Dastjerdi N, Soltany-Rezaee-Rad M, Sepehrizadeh $\mathrm{Z}$, et al. Identification of novel genes involved in gastric carcinogenesis by suppression subtractive hybridization. Hum Exp Toxicol 2015; 34: 3-11.

5. Kolahdoozan S, Sadjadi A, Radmard AR, Khademi H. Five common cancers in Iran. Arch Iran Med 2010; 13: 143-6.

6. McLean MH, El-Omar EM. Genetics of gastric cancer. Nat Rev Gastroenterol Hepatol 2014; 11: 664-74.

7. Giordano A, Cito L. Advances in gastric cancer prevention. World J Clin Oncol 2012 10; 3: 128-36.

8. Shi J, Qu YP, Hou P. Pathogenetic mechanisms in gastric cancer. World J Gastroenterol 2014; 20: 13804-19.

9. Nakamura J, Tanaka T, Kitajima Y, et al. Methylationmediated gene silencing as biomarkers of gastric cancer: a review. World J Gastroenterol 2014; 20: 11991-2006.

10. Liu HS, Xiao HS. MicroRNAs as potential biomarkers for gastric cancer. World J Gastroenterol 2014; 20: 12007-17.

11. Vogiatzi $P$, Vindigni $C$, Roviello F, et al. Deciphering the underlying genetic and epigenetic events leading to gastric carcinogenesis. J Cell Physiol 2007; 211: 287-95.

12. Calcagno DQ, Gigek CO, Chen ES, et al. DNA and histone methylation in gastric carcinogenesis. World J Gastroenterol 2013; 19: 1182-92.

13. Varga T, Czimmerer Z, Nagy L. PPARs are unique set of fatty acid regulated transcription factors controlling both lipid metabolism andinflammation. Biochim Biophys Acta 2011; 1812: 1007-22.
14. Tyagi $S$, Gupta $P$, Saini AS, et al. The peroxisome proliferator-activated receptor: A family of nuclear receptors role in various diseases. J Adv Pharm Technol Res 2011; 2: 236-40.

15. Ren P, Zhang Y, Huang Y, et al. Functions of peroxisome proliferator-activated receptor gamma (PPAR $\gamma)$ in gynecologic disorders. Clin Med Insights Oncol 2015; 9: 43-9.

16. Chandra V, Huang $P$, Hamuro $Y$, et al. Structure of the intact PPAR-gamma-RXR-nuclear receptor complex on DNA. Nature 2008; 456: 350-6.

17. Ogino S, Shima K, Baba Y, et al. Colorectal cancer expression of peroxisome proliferator-activated receptor gamma (PPARG, PPAR gamma) isassociated with good prognosis. Gastroenterology 2009; 136: 1242-50.

18. Peters JM, Shah YM, Gonzalez FJ. The role of peroxisome proliferator-activated receptors in carcinogenesis and chemoprevention. Nat Rev Cancer 2012; 12: 181-95.

19. Wang L, Waltenberger B, Pferschy-Wenzig EM, et al. Natural product agonists of peroxisome proliferator-activated receptor gamma (PPAR $\gamma$ ): a review. Biochem Pharmacol 2014; 92: 73-89.

20. Youssef J, Badr M. Peroxisome proliferator-activated receptors and cancer: challenges and opportunities. Br J Pharmacol 2011; 164: 68-82.

21. Kopelovich L, Fay JR, Glazer RI, Crowell JA. Peroxisome proliferator-activated receptor modulators as potential chemopreventive agents. Mol Cancer Ther 2002; 1: 357-63.

22. Theocharisa S, Margeli A, Kouraklis G. Peroxisome proliferator activated receptor-gamma ligands as potent antineoplastic agents. Curr Med Chem Anticancer Agents 2003; 3: 239-51.

23. Konturek PC, Kania J, Kukharsky V, et al. Implication of peroxisome proliferator-activated receptor gamma and proinflammatory cytokines in gastriccarcinogenesis: link to Helicobacter pylori-infection. J Pharmacol Sci 2004; 96: 134-43.

24. Takahashi N, Okumura T, Motomura W, et al. Activation of PPARgamma inhibits cell growth and induces apoptosis in human gastric cancer cells. FEBS Lett 1999; 455: 135-9.

25. Sato H, Ishihara S, Kawashima K, et al. Expression of peroxisome proliferator-activated receptor (PPAR)gamma in gastric cancer and inhibitory effects of PPAR gamma agonists. Br J Cancer 2000; 83: 1394-400.

26. Chen YX, Zhong XY, Qin YF, et al. 15d-PGJ2 inhibits cell growth and induces apoptosis of MCG-803 human gastric cancer cell line. World J Gastroenterol 2003; 9: 2149-53.

27. Lu J, Imamura K, Nomura S, et al. Chemopreventive effect of peroxisome proliferator-activated receptor gamma on gastric carcinogenesis in mice. Cancer Res 2005; 65: 4769-74.

28. Cheon CW, Kim DH, Kim DH, et al. Effects of ciglitazone and troglitazone on the proliferation of human stomach cancer cells. World J Gastroenterol 2009; 15: 310-20. 